\title{
The Impact of Using Information Systems in E-Management of Higher Education Organizations
}

\author{
Mohamed Abdulla Jabir ${ }^{1}$, Dr. Abdelrahman Elsharif Karrar² \\ ${ }^{1}$ Computer Centre, Nile College, Khartoum North, Sudan \\ ${ }^{2}$ College of Computer Science and Engineering, Taibah University, Al Madina Al Monawara, Saudi Arabia
}

\begin{abstract}
This study aimed to identify the impact of management information systems in the performance of employees and to identify the effects resulting from the use of these systems as well as to identify the most important problems that hinder the application of information systems in the Nile College (NC). To achieve the objectives of the study a questionnaire was developed and designed for data collection and distributed to the samples of (30) employees, the statistical package for social Sciences(SPSS) was used to analyze the data, and used statistical methods descriptive to know the perceptions of respondents to the dimensions of information systems and functionality, and analysis of multiple regression to test the validity of the study sample and the impact of the independent variables on the dependent variable, and analysis of variance.
\end{abstract}

Keywords: Information Systems, E-Management, Higher Education, Decision-Making

\section{Introduction}

Information systems are essential in the time of technology revolution. They have a very important role in decisionmaking in higher education institutions. Where it serves as the engine fuel resolving administrative and financial problems by using information systems to achieve an integrated view of the resources of the college and to optimize the use of resources.

To achieve this, we need to be able to deal with the vast amount of information in an effective way, to help make decisions for senior management. This help staff archives their duties with the required performance, to benefit from information systems in development of the administrative and academic process.

A unified system that provides a single point of access to all administrative departments in higher education institutions the university Information Systems offer a range of services for the administration such as admission and registration of students. it's the first step to save student data, find out the results, enables parents to follow up the of their children's academic level, attendance of lectures, they can pay fees remotely without having to come to the university.

An important department is financial and accounting because of the sensitivity of this department. It is considered the backbone of any organization, the success of this administration means the success of the university so the system provides all financial reports that's help in financial decision-making out of the report of the money record, balance sheet, receivable, payments and other reports by collecting financial information that provides a clearer view of the future, assessing sources of income, provide comprehensive reports on the financial situation of the university and the financial control of all the university's activities internally and externally and processed for use in senior management. Personnel affairs system save the employee $\mathrm{CV}$, vacations, promotions and annual salary increase. These systems serving harmonically and completely integrated access to important academic and administrative decisions aims to raise the quality of the educational process as a whole.

\section{Strategic Use of Information Systems in E- Management}

It is also worth to highlight that strategic use of information in running managerial activities across the internet and in emanagement platforms has changed the face of business because it has created new face of reliability. Consequently, the technique has created a strong archive and back up that can be used for data recovery purposes in case of disasters. Moreover, the method is considered to be a relatively cheap because it does not require additional costs of marinating the hardware once the underlying business data has been stored. In addition to that, strategic business has also changed the aspect business in the sense that e-management is substantially a type of business strategy that depends on sharing computing resources across networks instead of developing personal devices or local servers that are mandated with the task of handling different applications and business activities .

\section{Objectives}

1)Identify the most important contributory factors to improve possibility to use information systems.

2) Study the reality of the application of information systems in college.

3) Introduction of information systems in the planning and decision-making process in the institutions of higher education.

4) To find out the obstacles that prevent optimal usage of information systems. 


\section{International Journal of Science and Research (IJSR) \\ ISSN (Online): 2319-7064 \\ Index Copernicus Value (2015): 78.96 | Impact Factor (2015): 6.391}

\section{Hypothesis}

1)Role of information systems and their impact on quality and efficiency?

2)Benefit from using information systems and their impact on the effectiveness of the performance?

3)Is there are general acceptance of using information systems?

\section{Methods}

The investigator used descriptive and analytical approach in this study. a questionnaire was developed and design for the of data collection.

\section{Tools}

Interview - questionnaire - different sources. The practical application (integrated electronic information management system)

Sample

To achieve the objectives of the study a questionnaire was developed and design for the of data collection and distributed to the samples of (30) employees

\section{Statistical Technique}

The data has been analyzed using Statistical Package for Social Science (SPSS).

\section{Result}

Table 1: Distribution of the sample according to the preference of the system

\begin{tabular}{|c|c|c|c|}
\hline & Frequency & Valid percent & cumulative percent \\
\hline Strongly agree & 20 & 66.7 & 66.7 \\
\hline Agree & 9 & 30 & 96.7 \\
\hline Neutral & 1 & 3.3 & 100 \\
\hline Total & 30 & 100 & \\
\hline
\end{tabular}

Seen from table 1 that $(66.7 \%)$ of respondents strongly agreed, (30\%) agree and (3.3\%) are neutral. From this result, we find that the percentage of those who believe that the new system better $(96.7 \%)$ of respondents.

Table 2: Distribution of the sample according to the ease of use of the system

\begin{tabular}{|c|c|c|c|}
\hline & Frequency & Valid percent & cumulative percent \\
\hline Strongly agree & 14 & 46.7 & 46.7 \\
\hline Agree & 13 & 43.3 & 90 \\
\hline Neutral & 1 & 3.3 & 93.3 \\
\hline Disagree & 2 & 6.7 & 100 \\
\hline Total & 30 & 100 & \\
\hline
\end{tabular}

It is clear from table 2 that $(46.7 \%)$ strongly agreed and $(43.3 \%)$ agreed, and the percentage of those who do not agree $(6.7 \%)$, while neutral $(3.3 \%)$ this result shows us the proportion of those who believe that the easy-entry screens use $(90 \%)$ of the study sample.
Table 3: The distribution of the sample according to the output clarity and accuracy out of the system

\begin{tabular}{|c|c|c|c|}
\hline & Frequency & Valid percent & cumulative percent \\
\hline Strongly agree & 15 & 50.0 & 50.0 \\
\hline Agree & 11 & 36.7 & 86.7 \\
\hline Neutral & 4 & 13.3 & 100.0 \\
\hline Total & 30 & 100.0 & \\
\hline
\end{tabular}

Seen from the table 3 that $(50 \%)$ of respondents strongly agreed, (36.7\%) agree, (13.3\%) are neutral. From this result, we find that the percentage of those who believe that the new system outputs a clear and accurate $(86.7 \%)$ of the survey respondents.

Table 4: The distribution of the sample according to the ease of mobility in the system

\begin{tabular}{|c|c|c|c|}
\hline & Frequency & Valid percent & cumulative percent \\
\hline Strongly agree & 15 & 50.0 & 50.0 \\
\hline Agree & 13 & 43.3 & 93.3 \\
\hline Neutral & 1 & 3.3 & 96.7 \\
\hline Total & 1 & 3.3 & 100.0 \\
\hline
\end{tabular}

Seen from table 4 that (50\%) strongly agreed, (43.3\%) agreed, do not agree with $(3.3 \%)$, while neutral $(3.3 \%)$, this result shows us the percentage who see mobility in the system are $(94.3 \%)$ of the study sample.

Table 5: Distribution of respondents according to high security system

\begin{tabular}{|c|c|c|c|}
\hline & Frequency & Valid percent & cumulative percent \\
\hline Strongly agree & 15 & 50.0 & 50.0 \\
\hline Agree & 10 & 33.3 & 83.3 \\
\hline Neutral & 2 & 6.7 & 90.0 \\
\hline Total & 3 & 10.0 & 100.0 \\
\hline
\end{tabular}

Seen from table 5 that (50\%) strongly agreed, (33.3\%) agreed, $(10 \%)$ do not agree, while neutral are $(6.7 \%)$, this result shows us that $(83.3 \%)$ agreed high security in the system.

Table 6: Distribution of the sample according to the lack of use of paper

\begin{tabular}{|c|c|c|c|}
\hline & Frequency & Valid percent & cumulative percent \\
\hline Strongly agree & 16 & 53.3 & 53.3 \\
\hline Agree & 11 & 36.7 & 90.0 \\
\hline Neutral & 1 & 3.3 & 93.3 \\
\hline Total & 2 & 6.7 & 100.0 \\
\hline
\end{tabular}

Seen from table 6 that $(53.3 \%)$ strongly agreed, $(36.7 \%)$ agreed, do not agree with $(6.7 \%)$, while neutral are $(3.3 \%)$, this result shows us that $(90 \%)$ who believe that the system reduced the use of paper of the study sample.

\section{Findings}

Business organizations need a large amount of information in order to perform administrative functions, where the task of collecting data and turn it into information perform by employees. Development occurred in the handling of information in organizations, where its became as one of the topics of study, gathered the data and turn it into information by individuals, devices and transfer it into information to the 


\section{International Journal of Science and Research (IJSR) \\ ISSN (Online): 2319-7064 \\ Index Copernicus Value (2015): 78.96 Impact Factor (2015): 6.391}

user. Evaluation and making all the decisions classified under management information systems.

\subsection{The impact of using e-management in NC}

- The availability of the conviction and the desire of staff in dealing electronically using the new electronic system to facilitate touched in their daily business.

- Easy access to reports for General Director through communication between management levels.

- The speedy access to information without effort.

- Requiring each employee to access specific screen to maintain security, evaluate the performance of employees and find out defaulters.

- The new system reduced the use of paper, which is a significantly a positive impact on the work of the College and solve the problem of preservation and documentation.

\subsection{Obstacles to implement e-management in NC}

E-management faces some obstacles, whether human or regulatory constraints, technical or financial. Hence the problem of identifying those disagreeing on multiple and contrast the obstacles facing the application of emanagement in the administrative work procedures. The most important obstacles facing the application of e-management in the administrative work procedures, relying on personal experiences in doing the work, the lack of incentives offered to employees. adjusted management systems which are not computable in line with the application of electronic management systems. In Nile college, the obstacles were: -

- The lacks of adequate training for employees on the optimal use of a computer.

- Poor public awareness of the importance of the shift to egovernance and the advantages of its application.

- Weakness in the design of the internal network.

- Lack of precision in the output.

- The non-arrival information to the Beneficiary or the student directly.

- Routine administrative procedures hinder the transition to electronic administration.

- Internal network security weakness.

\section{Recommendations}

Deliberated steps to shift from traditional management to an electronic management to achieve the advantage.

- Administration must know the current status of the institution, of the available systems or unavailable material resources and qualified.

- Determine the team on each axis separately, follow up the implementation steps to ensure optimal performance going to run through deployment of electronic information systems.

- Start the analysis to develop a well thought plan for the organization.

- Use computer networks to reduce dependence on individuals and reduce the time to access the data through the use of information systems.

\section{Other recommendations}

- An establishment of infrastructure, build data center equipped with servers to expand the database and save it is a must.

- Train all employees effectively to use the computer and electronic management systems.

- Re-build functional structures to meet changing requirements.

- Review the rules and regulations commensurate with the business environment and requirements.

- Inform educate pubic dealing with the college.

\section{References}

[1] Broadbent, M. and Weill, P. (1997). Management by maxim: How business and IT managers can create IT infrastructures. Sloan Management Review, 38(3), 77-92.

[2] Byrd, T.A. and Turner, E.D. (2001). An exploratory analysis of the value of the skills of IT personnel: Their relationship to IS infrastructure and competitive advantage. Decision Sciences, 32(1), 21-54.

[3] Byrd, T.A. and Turner, E.D. (2000). An exploratory analysis of the information technology infrastructure flexibility construct. Journal of Management Information Systems, 17(1), 167-208.

[4] Gasser, L., The Integration of Computing and Routine Work. ACM Transactions on Office Information Systems.

[5] Hurtubise, R., 1984. Managing Information Systems: Concepts and Tools. West Hartford CT:Kumarian Press

[6] N., Abdalla, "Strategic Use of Information Systems in EManagement," International Journal of Advances in Electronics and Computer Science, 3(10), pp. 47-49. 2016. 